\title{
Awareness of Eco-label in Malaysia's Green Marketing Initiative
}

\author{
Nik Ramli Nik Abdul Rashid \\ Faculty of Business Management, Universiti Teknologi MARA Perlis \\ 026000, Arau Perlis, Malaysia
}

Tel: 60-4-9874-252Ｅ-mail: nikramli@perlis.uitm.edu.my

\begin{abstract}
Consumer awareness of the environment and preference for more environmentally benign products appears to be growing steadily around the developed world and also some developing countries. The Malaysian government too has responded very positively to this challenge. In 1996 Standards and Industrial Research Institute of Malaysia (SIRIM) lunched the national eco-labeling program verifying products according to environmental criteria such as Environmentally Degradable, Non-toxic Plastic Packaging Material, Hazardous Metal-Free Electrical and Electronic Equipment, Biodegradable Cleaning Agents and Recycled Paper. Federal Agriculture Marketing Authority (FAMA) has the Malaysia Best logo for environment friendly agriculture product and the Malaysian Energy Commission for energy efficient electrical products. But is the Malaysia consumer ready for the eco-label? Taking into consideration the infancy stage of the Malaysia green marketing initiative, traditional approach to evaluating local consumer receptiveness to the eco-label might not be suitable. This paper approaches the introduction of eco-label with two perspectives in mind. Firstly, while earlier studies from the western scholars use eco-label as a part of the augmented product, this study introduces eco-label as a separate moderating variable. Secondly, the choice of employees working in ISO14001 certified organization as the study population explore a potentially conducive place to initiate a systematic effort in developing a green consumer community. The result is very encouraging. This study has clearly shown that, with some exposure to environmental related experiences (such as those who were working with organization implementing the EMS) Malaysian consumer would indeed react positively to the eco-label. In fact, for situation that requires them to consider environmental aspects of a product that they wish to purchase, the eco-label will definitely be the crucial factor that will push them to make the right purchase choice.
\end{abstract}

Keywords: Eco-label, Environmental attitude, Knowledge of environmental issues, Green products, ISO14001

\section{Introduction}

The Product Certification Program, Malaysia's national labeling program, was launched in 1996 by the Standards and Industrial Research Institute of Malaysia (SIRIM). It is a single-attribute, seal-of-approval product certification program. As of March 1997, SIRIM's certification activities were delegated to a fully owned subsidiary SIRIM Quality Assurance Services (SIRIM QAS). This eco-labeling scheme would verify products according to environmental criteria such as Environmentally Degradable, Non-toxic Plastic Packaging Material, Hazardous Metal-Free Electrical and Electronic Equipment, Biodegradable Cleaning Agents and Recycled Paper.

Another relatively more active eco-labeling scheme is for agricultural products; one promoted by the Agricultural Department and Federal Agriculture Marketing Authority (FAMA), known through its SALM and Malaysia's Best logo, respectively. SALM (Skim Amalan Ladang Baik Malaysia) is a national program implemented by the Department of Agriculture to recognize and certify farms which adopt good agricultural practices (GAP), operate in an environmentally friendly way and yielding products that are of quality, safe and suitable for human consumption. Only agricultural produces from these certified farms could apply for the Malaysia Best eco-label.

There is also an eco-label that relates to efficient use of energy endorsed by the Malaysian Energy Commission. The commission was set up in 2001 to regulate and promote energy efficiency (EE) in line with national policies with the cooperation of interested stakeholders. The energy commission has established an energy labeling scheme for household appliances to assist Malaysian consumers. With the Energy Rating Label consumers will see the appliance energy performance at a glance and help them to compare products. Even though at the moment the Energy Rating Label is only used for refrigerators, the Energy Commission will expand its promotional efforts to encompass other energy efficient household appliances in the future. These encouraging developments could be evidence that the 
Malaysian business sector are not far behind in responding to challenges arising from demand made from the consumers for environmentally friendly products.

However, according to Chen (2003) these developments might not be originating from local causes because industries have only become more environment-conscious due to export market demand for environment-friendly goods or complying with instruction from oversea head office. Searching through literature also found very few studies done on the respond of local consumers toward the use of eco-label in purchase decisions. Taking into consideration the above discussion, the main question for this study is could Malaysian consumer awareness of an eco-label strengthen the preference they would give for the corresponding environment friendly product? The research framework consisting of all relevant variables is depicted in Figure 1 and will be elaborated further in the following section.

\section{(Insert Figure 1)}

\section{Literature Review}

\subsection{Eco-labels}

Eco-labels refer to a product's collective overall environmental performance (Giridhar, 1998). They are indicators of the environmental performance of a product, developed to try to prevent consumers from being confused over claims of environmental friendliness (Childs and Whiting, 1998). A sound eco-label program would look at the entire life cycle of the product including production, distribution, use and disposal. The first of such programs was the Germany's Blue Angel program, which began in 1978. A number of programs have been developed in other countries: The Swan (Nordic Eco labeling), Environmental Choice (Canada 1988), Eco Mark (Japan 1989), Green Seal (US 1990), Eco-Mark (India 1991) and Eco-label (EU 1993).

Eco-labels are potentially attractive instruments informing consumers (including institutions and governments that consume input materials and products) about the environmental impact of their purchasing decisions, while simultaneously providing producers with a tool for extracting market place preference and thus market share. Generically eco-labels can be classified into 2 categories: a) self-declaration claims and b) independent third-party claims. Self declaration claims are placed on a product by the manufacturer, retailer or marketer and may be made on a single attribute or an overall assessment of the product. Product claim could include "environment friendly"', "ozone friendly", "organic", "pesticide-free", "degradable", and "recyclable" which are usually described on the packaging. However, these claims are usually not independently verified. Independent third-party claims on the other hand are based on compliance with predetermined criteria, which are independently verified by a competent authority. The criteria are usually built on a product life-cycle approach.

A study by Teisl, Roe and Hick (2002) provided market-based evidence that consumers can respond positively to eco-labels and consequently contributed to the increased market share of the product concerned. Thogersen (2002) in a rather extensive study involving respondents from 4 different countries, found that large majority of them pay attention to eco-labels at least sometimes. Grankvist, Dahlstrand and Biel (2004) also found that information about environmental outcomes (which were either negative or positive) provided by eco-labels did influence product preference, especially those with strong concern for the environment. Apart from that, they also noted that women, graduate and young respondents showed positive attitude toward eco-labeled products. Loureiro and Lotade (2005) have identified consumers especially in much developed countries have shown their willingness to pay higher premium for eco-labeled products.

However, there are also some studies that highlighted the disagreement on whether or not eco-labeling or environmentally sound labeling programs may be effective tools to motivate consumer's response (Wessells et al., 1999). While discussing the strength and weaknesses of eco-labeling scheme Erskine and Collins (1997) concluded that, in practice, it would be very difficult to have a workable and effective eco-labeling scheme that could clearly contribute to improving the environment. Some studies even reported a weak correlation between environmental concern and the choice of eco-labeled product (Magnusson et al., 2001). Even consumer who know and trust a relevant environmental label will not use it due to information overload (Jacoby, 1984).

Thus, the above discussion showed that the use of eco-label in itself does not ensure positive response from the respondents. It seems to suggest that the use of eco-labels in assisting the eventual purchase decision can be influenced by other exogenous factors such as source credibility (Cary, Bhaskaran and Polonsky, 2004; Erskine and Collins, 1997; Nilsson, Tuncer and Thidell, 2004), the strength of the environmental concern (Grankvist, Dahlstrand and Biel, 2004), and availability of eco-labeled product on the retail shelf (Thogersen, 2000).

An observation common for all of the above studies is that the eco-labels are discussed as part of the augmented product and treated as a dependent variable. This is understandable taking into consideration the relatively advance stage of environmental awareness among western society and the easy availability of eco-labeled product in the retail outlets. This situation would not be applicable for a society who is relatively still unaware of the concept of a green product, much more for eco-labeled product. Thus, rather than focusing on eco-labels products as dependent variable, this study 
have attempted to uncover the independent role of eco-label moderating the relationship between predictor variables to its purchase decisions.

\subsection{Attitudes toward environmental protection}

Environmental attitude is defined as a learned predisposition to respond consistently favorable or unfavorable manner with respect to the environment. Overall, there has been consistent empirical evidence supporting a positive association between environmental attitude and behavior. These studies have also indicated that even if people have little knowledge about the environment they would still exhibit strong emotional attachment to environmental wellbeing (Ling-yee, 1997). Attitude, as opposed to knowledge and behavior, is the most significant predictor of consumers' willingness to pay more for ecologically favorable products (Laroche et. al., 2001). Some studies have also indicated that even though people have little knowledge about the environment they still exhibit strong emotional attachment to environmental wellbeing (Dispoto, 1997; Li Ling-yee, 1997). This study follows earlier studies in conceptualizing attitude toward environmental protection as a unidimensional construct (Noe and Snow, 1990; Minton and Rose, 1997; Sharifah et al., 2005).

\subsection{Environmental Knowledge}

The state of one's knowledge about an issue impacts significantly upon his or her decision making process. The importance of knowledge and the impact of lack of knowledge in the decision-making process have been demonstrated in numerous studies (Laroche et. al 2001; Verdugo, 1996, and Oskamp et al., 1991). This study has initially conceptualized consumer knowledge as having two dimensions, namely Knowledge of Environmental Issues and Knowledge of Green Product Features. The factor analysis of the 20 items measuring perceived knowledge of selected environmental issues were carried out and resulted in 3 dimensions (Table 1). The first factor consist of perceived knowledge respondents had concerning attributes of green products such as "no animal testing, natural ingredient cosmetics, wood product from sustainable forest, organic vegetables, ozone friendly aerosols, biodegradability and unleaded petrol". The second factor consists of respondent's perceived knowledge of general environmental issues such as "vanishing wildlife habitat, destruction of the rain forest, the greenhouse effect and pollution from pesticides". The last factor (concrete knowledge) consist of respondent's perceived knowledge regarding "waste management, hazardous waste and recycled material" which seems to be relevant issues related to their actual activities at their workplace or factory.

\section{(Insert Table 1)}

\subsection{Green Purchase Intention}

Green purchase intention (PI) is conceptualized as the probability and willingness of a person to give preference to products having eco-friendly features over other traditional products in their purchase considerations. The green product used for this study was the energy-saving bulb as compared to the traditional tungsten bulb. A detailed and graphical description of the two products was provided for comparison and the respondents were required to give their preferred product choice.

\section{Methodology}

The population for this study is employees of organizations that have successfully adopted the environmental management system ISO14001 since 1996. Questionnaires were either sent by "express mail" or delivered by hand to the environmental management representative (EMR), who would then be asked to randomly select 15 employees from their organization to be respondents for the survey. A total of 526 employees were then finally selected. The entire data collection period took approximately ten weeks to be completed. There are justifications for using this population. Firstly, due to the early stage of the green marketing initiatives in this country. Secondly, organization implementing the EMS would be a potentially conducive place to initiate a systematic effort in developing a green consumer community.

\section{Findings and Interpretation}

\subsection{Moderating Effect of Awareness of Eco-Labels Variables}

Hierarchical regression analysis was used to test the moderating effect of consumers' perception of eco-labels between concern for environmental protection and purchase intention. Based on the suggestions of Sharma et al. (1981), a three-step hierarchical regression analysis was conducted to test for a moderating effect. The independent variables were entered in the first step, the moderator variable was entered in the second step, and lastly the interaction between the moderator and the independent variables were entered. If the interaction term is statistically significant, a moderator effect is then present. The results of the analyses are discussed as below.

\section{(Insert Table 2)}

Table 2 above shows the results of the hierarchical regression analysis of the moderating effect of Awareness of Eco-Label between Environmental Attitude and Knowledge with Purchase Intention. The adjusted $\mathrm{R}^{2}$ and the F change 
are significant from step 1 to step 2 and from step 2 to step 3 with the introduction of the interaction terms indicating the moderating effect of eco-label awareness. For the interaction effect, the results indicated that the interaction between attitude and label awareness is significant $(\beta=.71, \mathrm{p}<.01)$. The interaction between knowledge of green product (knowledge $B$ ) and label awareness is also significant $(\beta=.49, \mathrm{p}<.05)$ as also with the interaction between concrete knowledge (knowledge $C$ ) and label awareness $(\beta=-.52, \mathrm{p}<.01)$. Lastly, the interaction between knowledge of environmental issues (knowledge $A$ ) and label awareness was found to be not significant.

Before final decision could be made the line graph was use to further analyze the effect of the moderating variable on the relationship between dependent and independent variables. Looking at Figure 2, it could be concluded that the relationship between Attitude toward Environmental Protection and Purchase Intention is decisively moderated by consumers' awareness of the relevant Eco-Label for the chosen product used in this study. The effect of high awareness of the eco-label in influencing the purchase of a green product is very strong for respondents having positive attitude toward the protection of the environment. The relationship is also positive for respondents with low awareness of eco-label, but as can be seen from the slope (beta), the effect on purchase intention is very much lower. The result indicated that the effect of attitude toward environmental protection on purchase intention is a crucial prerequisite, and can be further enhanced with the existence of an eco-label.

\section{(Insert Figure 2)}

Thus, we could now conclusively state that the higher the awareness of eco-label the stronger the relationship between attitude toward environmental protection and intention to purchase a product with environmental friendly features.

\section{(Insert Figure 3)}

The above Figure 3 displays the moderating effect of awareness of eco-label on the relationship between knowledge of green products and purchase intention. Respondents that have high awareness of eco-label (energy star) show a higher and positive inclination to purchase a green product (energy saving bulb) if they have better knowledge of them. Whereas respondents that have low awareness of eco-label show a negative relationship (i.e. though they would have more knowledge of the green product it would not influence them in their purchase). Thus, this clearly shows the influence awareness of eco-label has on the confidence of the respondents when making a purchase for a green product. It could also show that awareness of the relevant eco-label would help consumers distinguish between green products and ordinary products when they are confronted by a purchase decision making situation.

One other observation from the results is that respondents with high awareness of eco-label do not have as high beta as expectedly so (as compared to those having low awareness of the eco-label). This situation would probably be explained by the existence of other factors contributing to this relationship, namely as mentioned earlier, the role of attitude toward environmental protection. It could also be due to the fact that in the present circumstances the use of eco-label is very much limited, either from the perspective of the consumers or much so on the part of the manufacturer (marketer) when using these eco-labels in their marketing initiatives. In conclusion we could state that the higher the awareness of eco-label the stronger the relationship between knowledge of green product feature and intention to purchase a product with environmental friendly features.

Finally, the Figure 4 below shows the moderating effect of awareness of eco-label on the relationship between concrete knowledge and purchase intention. Respondents that have high awareness of eco-label show a stronger and positive inclination to purchase a green product (energy saving bulb) when they are more exposed to actual efforts in environmental protection at the workplace. In other word, consumer that has acquired knowledge of environmental protection through their own experience has higher intention to purchase a green product, only if they are made more aware of the environment friendly features of the product by the corresponding eco-label.

\section{(Insert Figure 4)}

On the other hand respondents that have low awareness of eco-label will show a negative relationship (i.e. even though they would have more knowledge arising from actual experience from the workplace, it would not influence them in their purchase intention, since there were no eco-label to inform them of the green features of the product). This clearly shows the impact of eco-label on the confidence of the respondents when making a purchase for a green product. Thus, we could now conclusively state that the higher the awareness of eco-label, the stronger the relationship between concrete knowledge and intention to purchase a product with environmental friendly features.

\section{Conclusions and Suggestion for future study}

This study have suggested that a person having some concern for the environment would have a stronger preference for purchasing a green product, if he is made much more aware of its environmental friendly features through the use of an eco-label.

The importance of an educational program directed toward the community at large, explaining the significance of an eco-label in any consumer purchase decisions, should be carried out hand-in-hand with the general effort to increase 
awareness for the need to protect the environment. It is very surprising indeed, even after launching a national eco-label since 1996, the level of consumer awareness regarding the local eco-labels is almost negligible. Effort in marketing the eco-label by the regulating authorities (government and SIRIM) should be on both ends of the marketing process, the producer and the final consumers. Another interesting finding, especially within the Malaysia's context (where the awareness for green products is still low) is that this study has been able to uncover some limited aspects of Malaysian consumers' reaction to the use of eco-label in their purchase intention for products with environment friendly features. Overall, this study has shown the positive moderating effect of awareness of eco-label between knowledge of green product and consumer intention to purchase. Two conclusions could be made with regard to this interesting result. Firstly, it shows that consumer need more information and to be made much more aware about products with green labels. The emphasis on giving clear information about eco-labels would be two-prong, as it would not only familiarize them with the labels itself but also their knowledge of green products. Failure to do this would mean they were handicapped as to making the best choice that would fulfill their intention to purchase a product with environment friendly feature, due to their inability to effectively discern between green and traditional products. Secondly, it seems that even for those consumers with high knowledge of green product and high awareness of corresponding green label, a positive response as is hoped for from them is not necessarily secured. There seems to be another missing element that could surge their intention of purchasing the product to a higher level. It could be assumed that the most relevant missing factor would be the trust in the eco-label itself. Future studies should be carried out, especially so for local third party eco-labels (such as SIRIM, Malaysia Best etc) and determine whether this assumption is true or otherwise.

As a final conclusion to the question of whether Malaysian consumers are ready for the eco-label? This study has clearly shown that, with some exposure to environmental related experiences (such as those who were working with organization implementing the EMS) Malaysian consumer would indeed react positively to the eco-label. In fact, for situation that requires them to consider environmental aspects of a product that they wish to purchase, the eco-label will definitely be the crucial factor that will push them to make the right purchase.

\section{References}

Bohlen, G., Schlegelmilch, B.B., \& Diamantopoulos, A. (1993). Measuring Ecological Concern: A Multi-construct Perspective. Journal of Marketing Management, 9, 415-430.

Cary, J., Bhaskaran, S., \& Polonsky, M. (2004). Green Marketing and EMS: Assessing potential consumer influence on EMS development in fresh food chains. A report for the Rural Industires Research and Development Corporation. No:04/175. Australian Government.

Chen, S.S. (2003). General activity of Life Cycle assessment in Malaysia. Environmental and $\quad$ Energy Technology Centre, SIRIM Berhad. Malaysia.

Childs, C. \& Whiting, S. (1998). Eco-labeling and the Green Consumers. Working papers from Sustainable Business Publications series. The Sustainable Business Initiative, Department of Environmental Science, University of Bradford, West Yorkshire. [Online] Available: http://www.brad.ac.uk/acad/envsci/SB/init.htm

Dispoto, R.G. (1997). Interrelationship among measures of environmental activity, emotionality, and knowledge. Educational and Psychological Measurement, 37(4), 451-459.

Erskine, C.C. \& Collins, L. (1997) Eco-labeling: Success or Failure. The Environmentalist, 17, 125-133.

Giridhar, T.R. (1998) Eco-labelling: A comparative analysis. Chemical Business, 12(7), 95.

Grankvist, G., Dahlstrand, U., \& Biel, A. (2004). The impact of environmental labeling on consumer preference: Negative versus positive labels. Journal of Consumer Policy, 27, 213-230.

Jacoby, J. (1984). Perspective of information overload. Journal of Consumer Research, 11, 569-573.

Laroche, M., Bergeron, J. \& Barbaro-Forleo, G. (2001). Targeting consumer who are willing to pay more for environmentally friendly products. Journal of Consumer Marketing, 18(6), 503-520.

Li, Ling-yee (1997). Effect of collectivist orientation and ecological attitude on actual environmental commitment: The moderating role of consumer demographic and product involvement. Journal of International Consumer Marketing, 9(4), 31- 54.

Loureiro, M. L., \& Lotade, J. (2005). Do fair trade and eco-labels in coffee wake up the consumer conscience? Ecological Economics, 53(1), April, 129-138.

Magnusson, M.K., Arvola, A., Koivisto Hursti, U.K., Aberg, L. \& Sjoden, P.O. (2001). Attitudes toward organic foods among Swedish consumers. British Food Journal. 103, 209-227.

Minton, A.P., \& Rose, R.L. (1997). The effects of environmental concern on environmentally friendly consumer behavior: an exploratory study. Journal ofBusiness Research. 40, 37-48. 
Nilsson, H., Tuncer, B., \& Thidell, A. (2004). The use of eco-labeling like initiatives on food products to promote quality assurance - is there enough credibility? Journal of Cleaner Production, 12, 517-526.

Noe, F.P., \& Snow, R. (1990). The new environmental paradigm and further scale analysis. Journal of Environmental Education, 21, 20-26.

Oskamp, S., Harrington, M.M., Edwards, T.C., Sherwood, D.L., Okuda, S.M. \& Swanson, D.C. (1991) Factors influencing household recycling behavior. Environment and Behavior, 23, 494 - 519.

Teisl, M.F., Roe, B., \& Hicks, R.L. (2002). Can Eco-labels Tune a Market? Evidence from Dolphin Safe Labeling. Journal of Environmental Economics and Management, 43, 339-359.

Sharifah A. Haron, Laily Paim, \& Nurizan Yahaya. (2005). Toward sustainable consumption: An examination of environmental knowledge among Malaysia. International Journal of Marketing Research, 18, 426-436.

Sharma, S., Durand, R. M. \& Gur-Arie, O. (1981). Identification and Analysis of Moderator Variables. Journal of Marketing Research, 18(3), 291-300.

Thogersen, J. (2002). Promoting “Green" Consumer Behavior with Eco-Labels. New Tools for Environmental Protection: Education, Information and Voluntary Measures (editors: Dietz and Stern). National Academy Press. Washington DC.

Thogersen, J. (2000). Knowledge barriers to sustainable consumption. In P. F. Bone, K. R. France, \& J. Wiener (Eds.), Marketing and public policy conference proceedings 2000. 10, 29-39. Chicago: American Marketing Association.

Wessells, C. R., Johnston, R. J., \& Donath, H. (1999). Assessing Consumer Preferences for Ecolabeled Seafood: The Influence of Species, Certifier, and Household Attriobutes. American Journal of Agricultural Economics, 81(5), 1084-1089.

Verdugo, C. V. (1996). A structural model of reuse and recycling in Mexico. Environment and Behavior, $28,664-696$. 
Table 1. Factor Analysis for Perceived Environmental Knowledge

Factor Loading

\begin{tabular}{lll}
1 & 2 & 3 \\
\hline
\end{tabular}

Knowledge of Green Products
a. Biodegradability
$\begin{array}{lll}.63 & .18 & .19\end{array}$
b. Wood product from sustainable forest $\quad \begin{array}{lll}.76 & .22\end{array}$
c. No animal testing
.77

$.17 \quad .05$
d. Ozone friendly aerosols

$.72 \quad .21$
e. Organic vegetable
.76

$.30 \quad .03$
f. Natural ingredient cosmetics
.76
g. Minimum packaging materials
h. Unleaded petrol

$\begin{array}{lrrrr} & .76 & .22 & .16 \\ .61 & .23 & .31 & \end{array}$

\section{Knowledge of Environmental Issues}
a. Greenhouse effects
$\begin{array}{lll}.29 & .75 & .29\end{array}$
b. Pollution from pesticides
$.30 \quad .75$
$.75 \quad .23$
c. Destruction of rainforest
.34
.79
d. Vanishing wildlife habitat
$\begin{array}{lll}.33 & \mathbf{8 0} & .09\end{array}$

\section{Concrete Knowledge}
a. Hazardous waste
.06
.24
.83
b. Waste Management
$.07 \quad .20$
.86
c. Recycled materials

$\begin{array}{lll}.27 & .29 & .62\end{array}$

Eigen values

$\begin{array}{lll}9.79 & 2.52 & 1.27 \\ 26.50 & 23.72\end{array}$

17.73

Percentage of variance .92

Kaiser-Meyer-Olkin .00

Bartlett's Test of Sphercity

$.91 \quad .91$
cross factor loading)

$.91 \quad .91$
cross factor loading)

.81

Reliability

(Note: 5 items were dropped due to cross factor loading) 
Table 2. Moderating effect of Awareness of Eco-Label on the Relationship between Ecological Concern and Purchase Intention

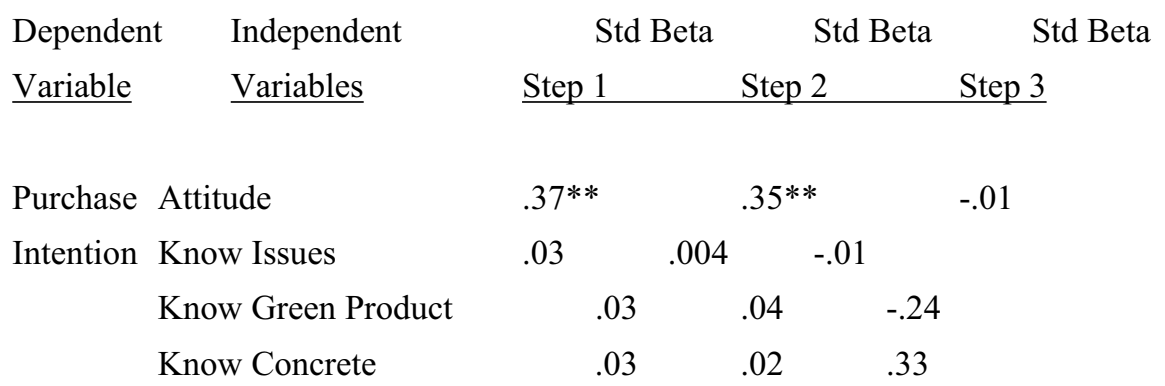

\section{Moderating}

Awareness of Eco Label

\section{Interaction Terms}

Attitude X Label Aware

Knowledge A X Label Aware

Knowledge B X Label Aware

$.49 *$

Knowledge C X Label Awareness

\begin{tabular}{lllll} 
Adjusted $\mathrm{R}^{2}$ & \multicolumn{1}{c}{.15} & \multicolumn{2}{c}{.16} & \multicolumn{1}{c}{.19} \\
$\mathrm{R}^{2}$ change & .15 & \multicolumn{2}{c}{.013} & \multicolumn{2}{c}{.034} \\
F change & 22.83 & & 7.80 & 5.29 \\
Sig. F change & & .000 & .005 & .000 \\
\hline
\end{tabular}

$p<01 * *, \quad p<05$ * 


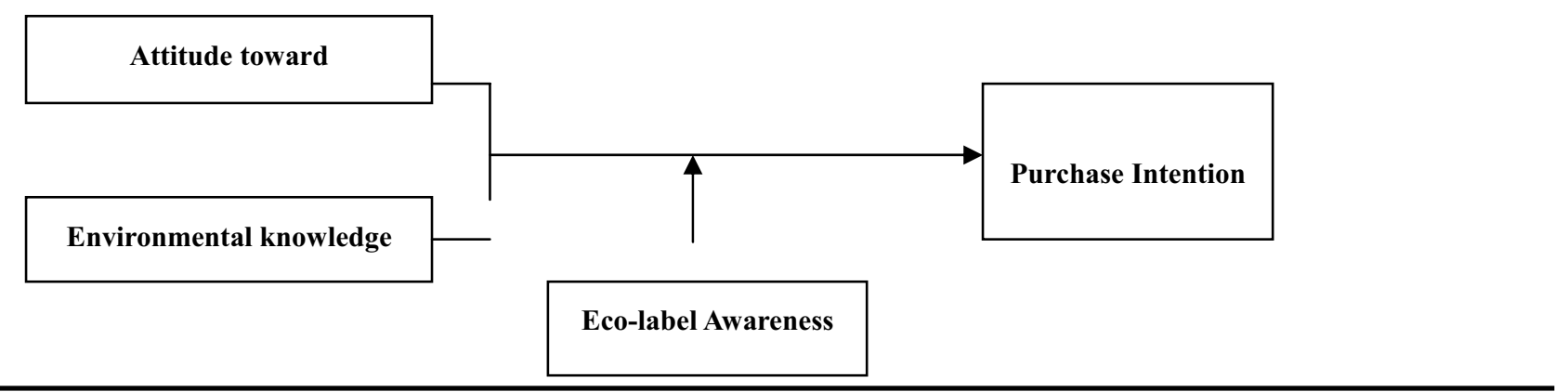

Figure 1. Research framework

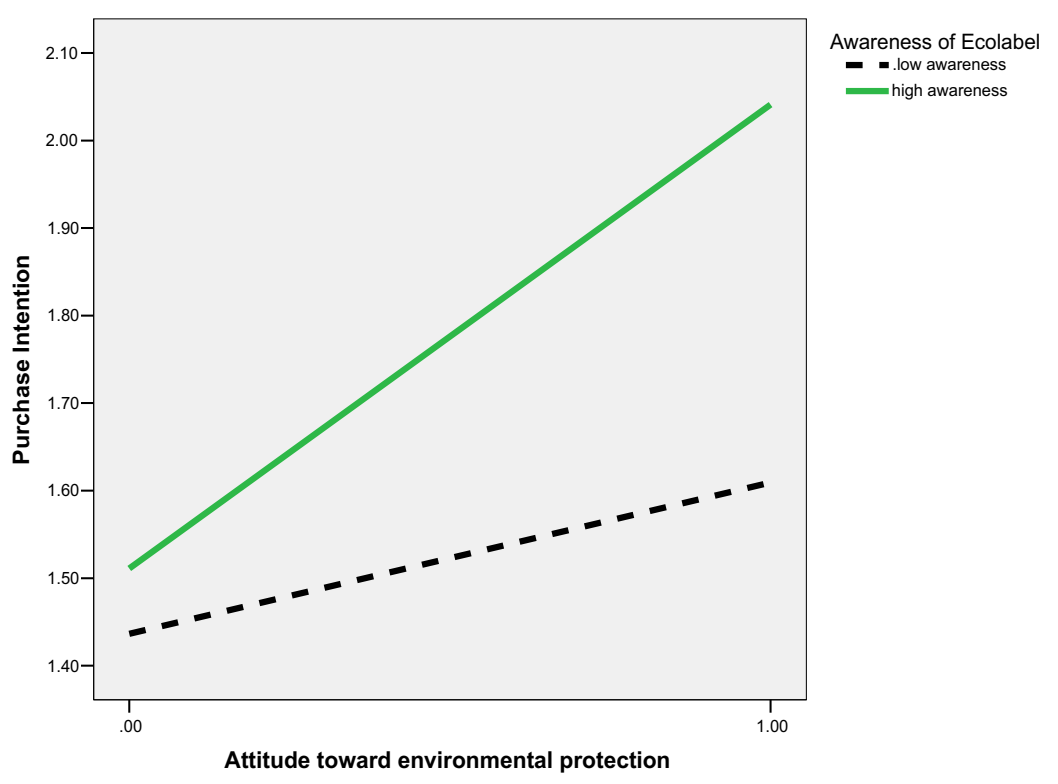

Figure 2. The impact of label awareness on the relationship between attitude toward environmental protection and purchase intention 


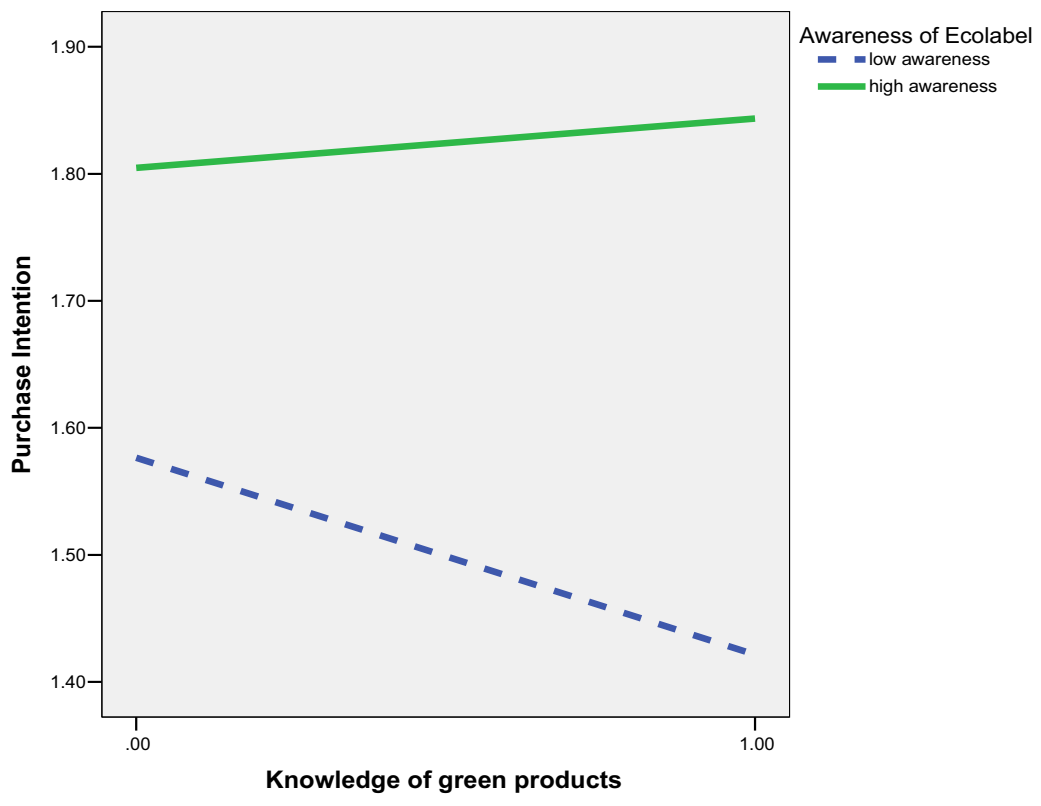

Figure 3. The impact of awareness of eco-label on the relationship between knowledge of green products and purchase intention

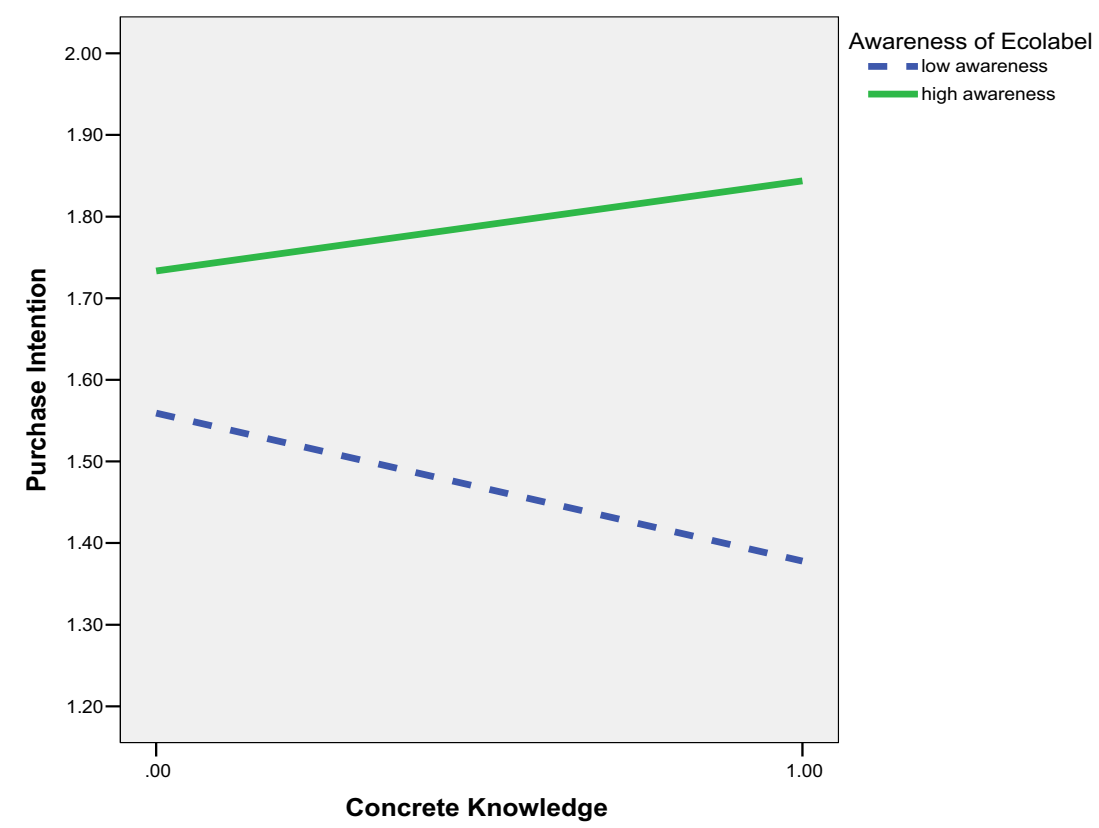

Figure 4. The impact of awareness of eco-label on the relationship between concrete knowledge and purchase intention 